\title{
Anatomic Study of the Right Coronary Artery in Pigs. Feature Review in Comparison with the Human Artery
}

\author{
Estudio Anatómico de la Arteria Coronaria Derecha en Cerdos. \\ Revisión de sus Características en Comparación con la del Humano
}

Gómez, F. A.* \& Ballesteros, L. E.**

GÓMEZ, F. A. \& BALLESTEROS, L. E. Anatomic study of the right coronary artery in pigs. feature review in comparison with the human artery. Int. J. Morphol., 31(4):1289-1296, 2013.

SUMMARY: A few studies conducted on the morphology of coronary arteries in pigs emphasize the description of its course and number of branches. The objective of this study was to determine the anatomic expression of the right coronary artery (RCA) in pigs of commercial stock. One hundred and fifty eight hearts obtained from pigs destined to sacrifice were studied. The RCA were perfused with polyester resin (Palatal 85\% and Styrene 15\%) and then subjected to $\mathrm{KOH}$ infusion for 5 minutes to release the subepicardial fat. Diameters were measured and courses were evaluated. Results: The diameter of the RCA in its proximal portion was 3.85 mm (SD 0.75). The right artery of the cone originated from the RCA in 100 specimens $(63.3 \%)$ and from the aorta (third coronary) in 8 specimens $(5.1 \%)$. The posterior interventricular branch (PIB) reached the apex in the majority of the cases $(49.3 \%)$. Its proximal diameter was 2.75 $\mathrm{mm}$ (SD 0.61). The sinoatrial node branch (SAB) and the atrioventricular node branch (AVNB) originated from the RCA in $100 \%$ of the specimens. The diameters of the SAB and AVNB were $1.1 \mathrm{~mm}$ (SD 0.30) and $1.16 \mathrm{~mm}$ (SD 0.30), respectively. The posterior right diagonal branch was not observed. There is an agreement with most prior studies with respect to both SAB and AVNB emerging from the RCA. Morphometric and qualitative knowledge of the RCA and its branches in pigs is relevant for the design of procedural and hemodynamic models.

KEY WORDS: Pig; Right coronary artery, Sinoatrial node branch; right branch of the cone.

\section{INTRODUCTION}

The right coronary artery (RCA) emerges from the homonym aortic sinus and irrigates both the right atrium and ventricle. The RCA is divided into three segments: The first segment runs along the anterior surface of the atrioventricular sulcus, the second runs along the posterior aspect of said sulcus, and the third segment is formed as a product of its bifurcation near the crux cordis (the site of confluence of the atrioventricular and posterior interventricular sulci) in the left retroventricular branch (LRVB) and posterior interventricular branch (PIB) (Schlesinger, 1940; Sahni et al., 2008).

The sinoatrial node branch (SAB), two or three atrial branches, the right branch of the cone (RBC), anterior ventricular branches, and one right marginal branch (RMB) emerge from the RCA (Sahni et al.). When the RBC emerges directly from the right aortic sinus it is known as the third coronary, a morphologic feature that has not been described in pig hearts whereas in humans it has been reported with a frequency of 25-35\% (Miyazaki \& Kato, 1988; Kosar et al., 2009; Ballesteros et al., 2011).

Atrial and ventricular branches and the atrioventricular node branch (AVNB) stem from the second segment, although this structure has been reported to emerge from the LRVB (Sahni et al.).

Right and left ventricular branches and septal branches derived from the PIB have been described in pigs, but no reference has been made as to the morphometric aspects related to the diameter and length of this segment (Crick et al., 1998; Sahni et al.). There is variability as to the site of finalization of the PIB in humans; it has been said to end up more frequently at the inferior segment of the posterior interventricular sulcus (PIS) and the apex, and with a lower frequency at the mid and upper segments of this sulcus

* DMV, Candidate Magister of Science Basic Biomedic. Universidad Industrial de Santander. Bucaramanga, Colombia.

** MD, MSc, Basic Sciences Department Titular Professor - Health Faculty - Universidad Industrial de Santander. Bucaramanga, Colombia. 
(James \& Burch, 1958; Baptista et al., 1989; Nerantzis et al., 1994; Ortale et al., 2005).

In recent years pigs have commonly been used for animal experimentation, thus making them the appropriate model for heterologous organ transplants (Sisson et al., 1995; Crick et al.; López et al., 2004). Knowing the morphologic expression patterns of the coronary arteries and its branches is of vital importance for imaging procedures, hemodynamic interventions, and surgical operations that are based on this particular knowledge (Cavalcanti et al., 1995). Literature on the coronary circulation in pigs is sparse, although the arterial distribution of this species has been said to be similar to that of humans (Lumb \& Singletary, 1962; Kato et al., 1987; van Andel et al., 2003). Since the existing works have refined the qualitative features of this irrigation, this work is intended to enrich knowledge on the anatomic and morphometric features of the RCA through the evaluation of a sample of commercial pigs (Pietrain, Landrace Belga and Large White mixed breeds) and to point out similarities and differences of this vascular structure in the hearts of pigs and humans.

\section{MATERIAL AND METHOD}

This cross-over descriptive study assessed the RCA of 158 hearts obtained from pigs destined to sacrifice and provided by the Vijagual refrigerating plant in BucaramangaColombia. The samples were subjected to exsanguination for 6 hours. After its ostium was channeled, the RCA was perfused with polyester resin (palatal GP41L 85\% and styrene $15 \%$ ) and stained with mineral red; to facilitate their setting the anatomic pieces were kept immersed in water for 24 hours. Then the hearts were impregnated with $\mathrm{KOH}$ for 5 minutes with the purpose of liberating the subepicardial fat and then they were set in 5\% formaldehyde solution.

The proximal, mid, and distal diameters of the RCA were recorded, as well as the proximal diameter of its collateral branches; similarly, the distance between the point of finalization of the PIB and the cardiac apex was determined. PIBs ending at the upper or mid thirds of the PIS were considered short; those ending at the lower segment of the said sulcus were considered as medium in length, and those reaching the apex or even the anterior aspect of the left ventricle were rated as long. The courses and territories irrigated by the branches emerging from the RCA were determined. Morphometric measures were taken with a digital caliper (Mitutoyo ${ }^{\circledR}$ ).

All anatomic pieces were photographed in order to support the recorded findings. The continuous variables were expressed as means and standard deviations; the discrete variables were reported as frequencies and percentages. Continuous variables were analyzed using t test, whereas discrete ones were analyzed using Pearson's c2 and Fisher's exact test. The statistical program "Epi - Info 3,5.3" was used for result analysis.

\section{RESULTS}

The mean weight of the 158 hearts evaluated obtained from pigs sacrificed at $90 \mathrm{~kg}$ was $360 \mathrm{~g}$ (SD 61.21). A mean of 3.5 ventricular branches emerged from the first segment of the RCA and 2.5 branches from the second segment (Fig. 1).

The proximal diameter of the RCA was $3.85 \mathrm{~mm}$ (SD 0.75 ), the mid diameter was $3.13 \mathrm{~mm}$ (SD 0.66), and the distal diameter was $2.79 \mathrm{~mm}$ (SD 0.57). The PIB was observed to end up at the level of the apex in 78 specimens (49.3\%), whereas with a lower frequency, in 6 hearts (3.9\%) it ended up at the proximal third of the PIS (Table I) (Fig. 2 ). The difference between the number of long and short PIBs was statistically significant $(\mathrm{p}=0.0000)$.

The distance of finalization of both short and mid PIBs with respect to the apex was $32.1 \mathrm{~mm}$ (SD 12.15). The diameters of this artery measured at its upper, mid, and lower segments were $2.75 \mathrm{~mm}$ (SD 0.61); $2.14 \mathrm{~mm}$ (SD 0.44); and $1.42 \mathrm{~mm}$ (SD 0.36), respectively. The emergence of 3.3 branches irrigating the right ventricle and 2 branches to the posterior aspect of the left ventricle was observed. The distal segments of the PIB and the anterior interventricular branch showed anastomoses in 12 specimens (7.6\%), of which seven corresponded to females $(58 \%)$ and 5 to males $(42 \%)$. LRVBs originating from the crux cordis are characterized by having a considerably smaller diameter than the PIB and a "U-shaped" proximal segment from which the AVNB usually stems out. It finally provides 2 or 3 small branches to the medial segment of the posterior wall of the left ventricle. A very large LRVB running horizontally to reach the left margin of the heart and providing 4 posterior left ventricular branches was observed in two cases.

RBC was found in 100 specimens $(63.3 \%)$, with a mean diameter of $1.57 \mathrm{~mm}$ (SD 0.56). The distance from its origin to the right coronary ostium was $3.62 \mathrm{~mm}$ (SD 2.75). It was found to end up at the level of the cone in $41 \%$ of the cases, at the upper third of the anterior wall of the right ventricle in $19 \%$, at the mid third in $37 \%$, and at the lower third of the said wall in $3 \%$ of the cases. In eight hearts 


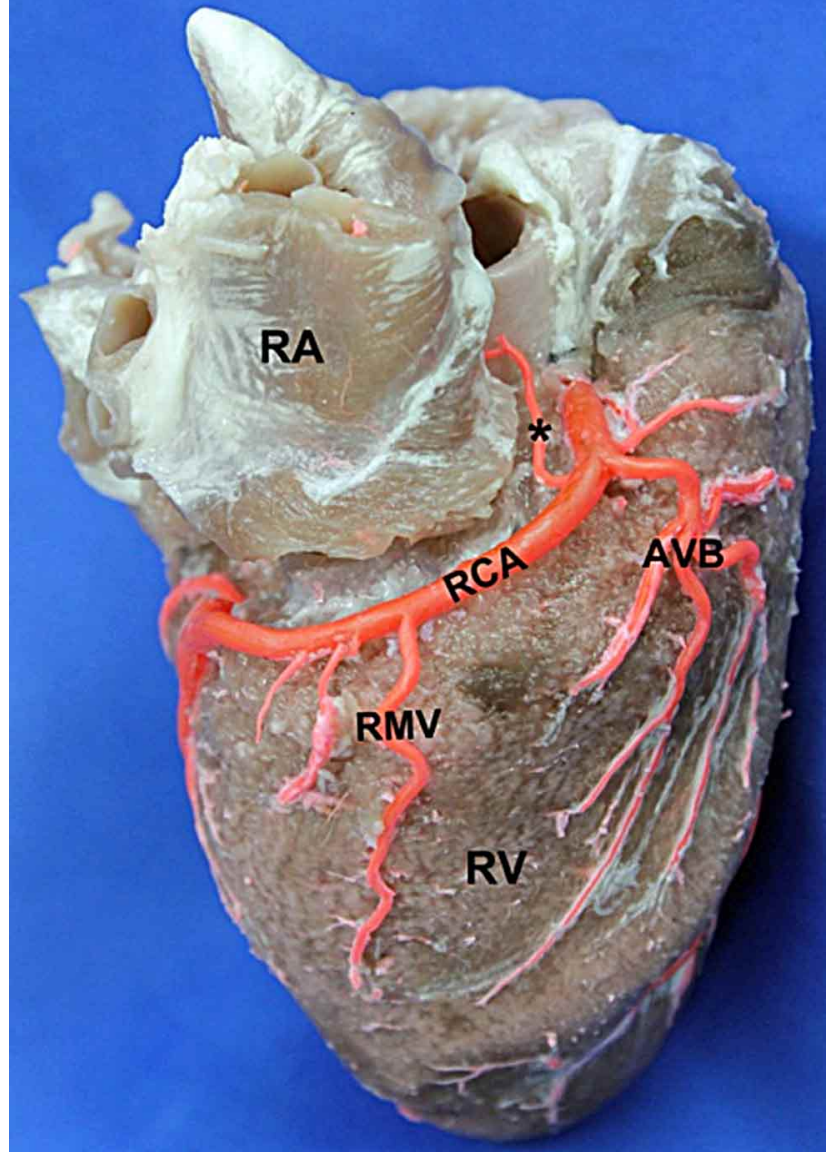

Fig.1. Anterior view of the heart. RV: Right Ventricle. RA: Right Atrium. RCA: Right coronary artery. AVB: Anterior ventricular branches. RMB: Right marginal branch. (*): Sino Atrial Branch.

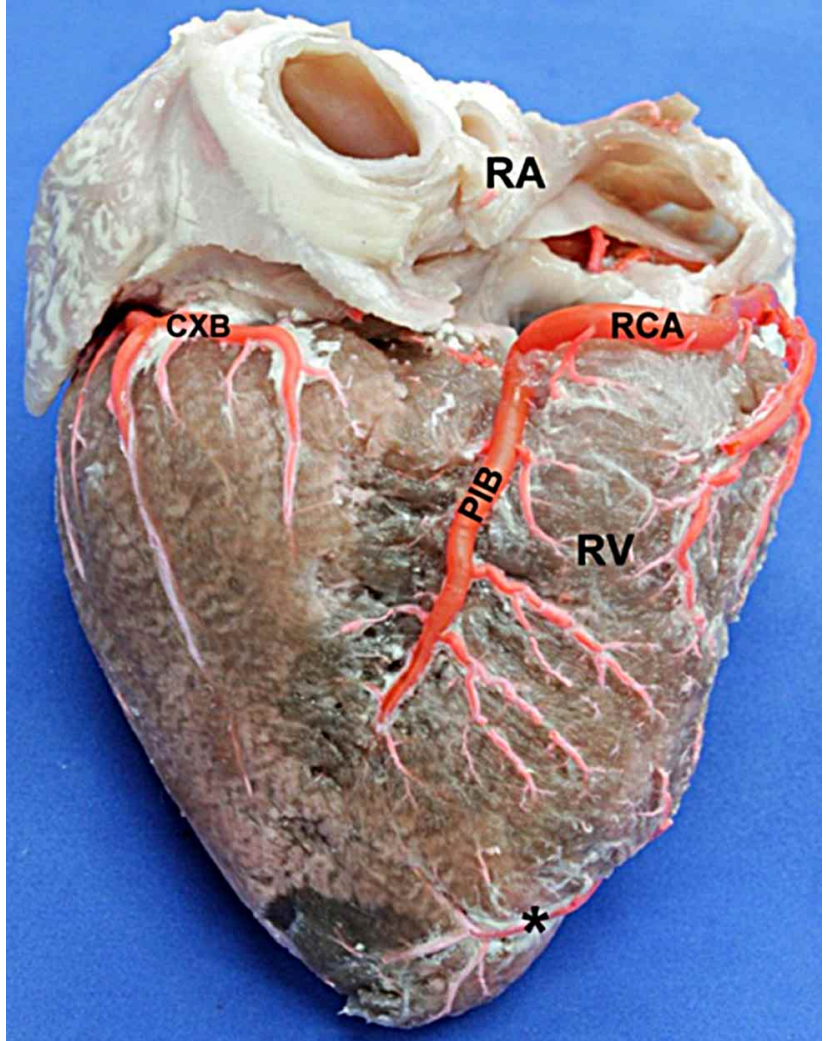

Fig. 2. Posterior view of the heart. RV: Right ventricle. RA: Right atrium. RCA: Right coronary artery. PIB: Posterior interventricular branch ending in the middle third of sulcus homonym. CXB: Circumflex branch. (*): Branch of anterior interventricular branch.

Table I. Finish of posterior interventricular branch (PIB) in homonym groove (PIG), cardiac apex and anterior left ventricular surface, by sex discrimination.

\begin{tabular}{lcccccc}
\hline Right edge of the heart & Total sample & $\boldsymbol{\%}$ & Males & $\boldsymbol{\%}$ & Females & $\%$ \\
\hline Upper third & 64 & 42.6 & 34 & 41 & 30 & 46.2 \\
Middle third & 78 & 52 & 46 & 55.4 & 32 & 49.2 \\
Lower third & 6 & 5.4 & 3 & 3.6 & 3 & 4.6 \\
Total & 148 & 100 & 83 & 100 & 65 & 100 \\
\hline
\end{tabular}

$(5.1 \%)$ the RBC emerged directly from the right aortic sinus (third coronary). Its irrigation territory comprised the cone and part of the upper and mid segments of the anterior wall of the right ventricle (Fig. 3).

The RMB was found in 148 specimens (93.7\%), with a mean diameter of $1.30 \mathrm{~mm}$ (SD 0.42). It ended with a greater frequency at the mid third of the right margin of the heart in 78 cases $(52 \%)$, of which $46(55.4 \%)$ were males and $32(49.2 \%)$ females, a non-significant difference $(\mathrm{p}=0.45)$ (Fig. 1) (Table II).
The SAB originated from the RCA in $100 \%$ of the samples, and the distance from its emergence to the right coronary ostium was $17.53 \mathrm{~mm}$ (SD 5.25). Its mean diameter was $1.11 \mathrm{~mm}$ (SD 0.30) (Fig. 1). Similarly, the AVNB originated from the RCA in $100 \%$ of the specimens, with a mean diameter of $1.16 \mathrm{~mm}$ (SD 0.30). In 111 hearts (85\%) it originated from the LRVB, whereas in 19 samples $(15 \%)$ it originated directly from the RCA. When it stemmed out of the LRVB, the mean distance from its emergence to the bifurcation of the RCA was $9.21 \mathrm{~mm}$ (SD 4.27) (Fig. 4). The posterior right diagonal artery was not found in anyone of the specimens. 


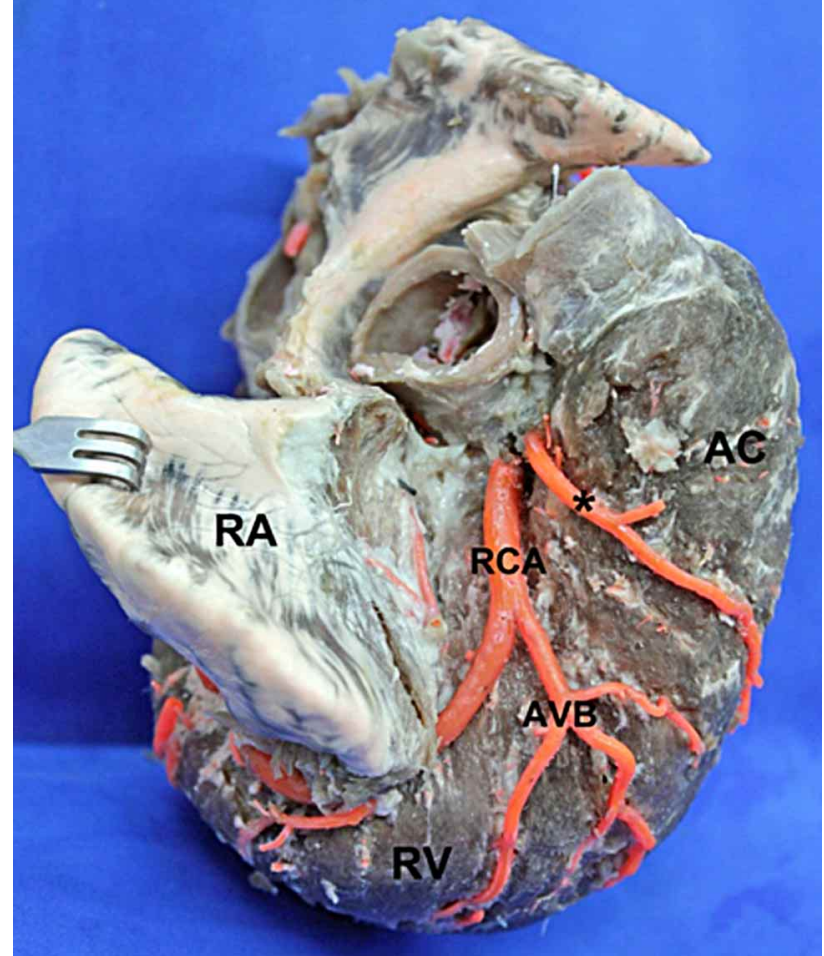

Fig. 3. Anterosuperior view of the heart. RA: Right atrium. RV: Right ventricle. AC: Arteriosus conus. RCA: Right coronary artery. (*): Cone right branch originating from the right aortic sinus (third coronary). AVB: Anterior ventricular branches.

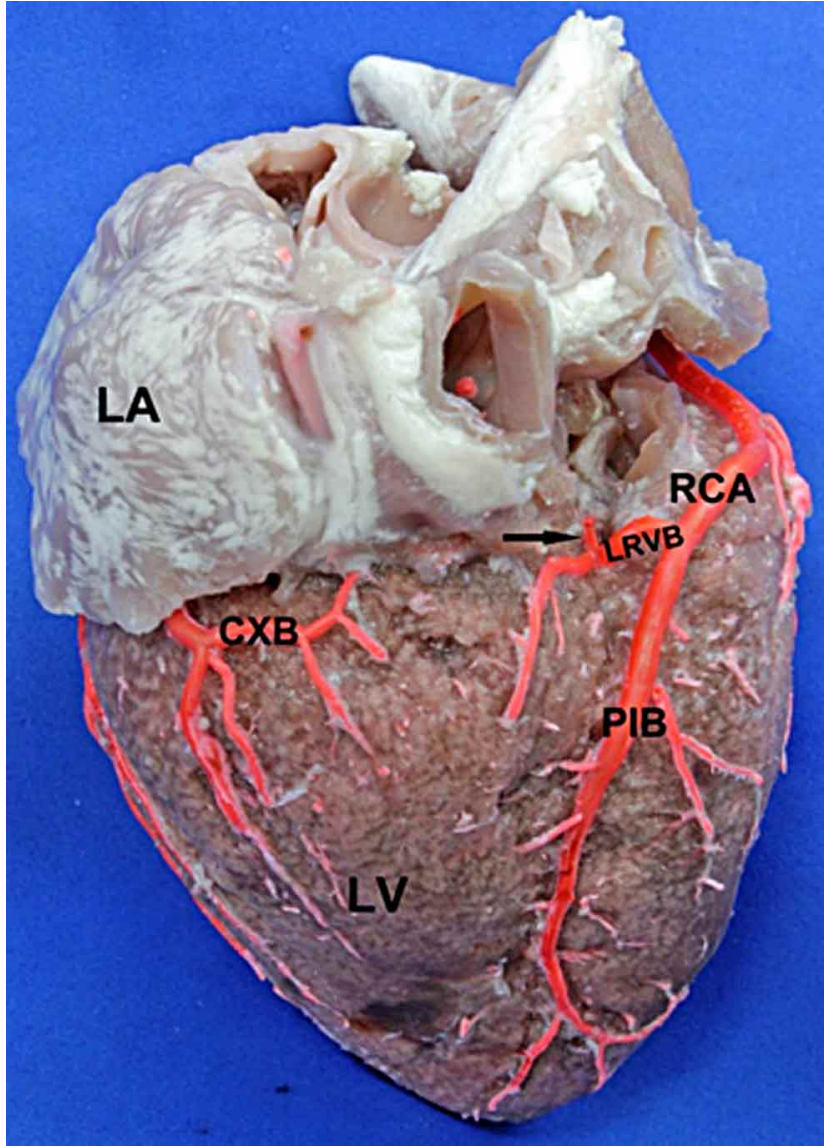

Fig. 4. Posterior view of the heart. LV: Left ventricle. LA: Left atrium. RCA: Right coronary artery. PIB: Posterior interventricular branch. LRVB: Left retroventricular branch. Arrow: atrioventricular node branch. CXB: Circumflex branch.

Table II. Finish of right marginal branch (RMB) at the right edge of the heart, by sex discrimination.

\begin{tabular}{lcccccc}
\hline Right edge of the heart & Total sample & $\boldsymbol{\%}$ & Males & $\boldsymbol{\%}$ & Females & $\%$ \\
\hline Upper third & 64 & 42.6 & 34 & 41 & 30 & 46.2 \\
Middle third & 78 & 52 & 46 & 55.4 & 32 & 49.2 \\
Lower third & 6 & 5.4 & 3 & 3.6 & 3 & 4.6 \\
Total & 148 & 100 & 83 & 100 & 65 & 100 \\
\hline
\end{tabular}

\section{DISCUSSION}

Prior studies in pigs fail to state the diameters of the different segments of the RCA. In humans (Vieweg et al., 1976; Sahni \& Jit, 1989; Dodge et al., 1992; Zindrou et al., 2006; Ballesteros et al., 2011) the diameters of the proximal segment of the RCA have been reported to range from 3.4$4.1 \mathrm{~mm}$, in agreement with our findings $(3.85 \mathrm{~mm})$. The relative difference in the numbers can be attributed to the size of the specimens evaluated in each one of the investigations referred to. Additionally, the diverse studies in humans fail to record the diameters of the distal segment of the RCA. The number of ventricular branches of the anterior and posterior segments of the RCA reported by Sahni et al., is similar to our findings (namely, 3.5 and 2.5 branches).

The finalization of the PIA and its morphometry in pigs has not been referred to in prior studies. Sahni et al., indicates that this artery in its segment final is divided into right and 
left branches; a feature that was found only in 1 case in our series (Fig. 6). The PIB has been reported to end up at the proximal and mid thirds of the homonym sulcus in a range of $25-35 \%$ in humans, whereas its ending at the level of the distal third, the apex and anterior aspect of the left ventricle has been reported in a range of the 67.4-75\% (James, 1965; Nerantzis et al.; Margaris et al., 1997; Ballesteros et al., 2011). These numbers are similar to the ones observed in our study. In the presence of short PIBs, compensation mechanisms arise that allow for the posteroinferior wall of the heart receiving an appropriate irrigation, such as the presence of the anterior interventricular branch that goes beyond the apex and ends up at the posterior aspect. The presence of 3 or 4 right ventricular branches emerging from the PIB observed in our study is consistent with the report by Sahni et al. The proximal and mid diameters of the PIB in our study $(2.75 \mathrm{~mm}$ and $2.14 \mathrm{~mm})$ are greater than those reported by Ballesteros et al. (2011), in human hearts (2.04 $\mathrm{mm}$ and $1.7 \mathrm{~mm}$ ). It should be borne in mind that the weight of the specimens studied in that report was $304 \mathrm{~g}$, so a similarity between the diameters of the coronary vessels in humans and pigs can be deducted after the individuals have been adjusted for weight.

The $\mathrm{RBC}$ in pigs has been described as the first branch that stems out of the RCA and that irrigates the upper segment of the anterior wall of the right ventricle. This branch does not anastomose with the left branch of the cone (Sahni et al.). This morphologic expression is consistent with the findings of our work. Similarly, no prior study in pigs has referred to the RBC as being originated from the aorta (Lumb et al.; Weaver et al., 1986; Crick et al.; Sahni et al.). In our series, this finding was observed in 8 specimens (5.1\%). The presence of third coronary artery has been described in humans in a range of 25-35\% (Miyazaki et al.; Kalpana et al., 2003; Kosar et al.; Ballesteros et al., 2011), although lower incidences have been reported $(8-11 \%)$ in some studies (Stankovic \& Jesic, 2004; Cademartiri et al., 2008). This vascular expression can be considered protect the anterior wall of the right ventricle against ischemia because of its anastomoses with branches of the anterior interventricular artery.

The RMB has been reported in pigs with a frequency of $60 \%$ as a small branch emerging from the RCA at the right margin of the heart (Sahni et al.); this number differs from our study, which observed this structure in $93.7 \%$ of the cases, but is consistent with the said study when it indicated that it ends up in the majority of the cases at the mid third of the acute margin of the heart. The RMB occurs with a high frequency $(95.5 \%)$ and a greater diameter $(1.55$ $\mathrm{mm}$ ) and length in humans than in pigs. It ends up in $41 \%$ of the cases at the lower third of the acute margin or at the cardiac apex (Ballesteros et al., 2011).
In this study the SAB emerged as a branch of the RCA in $100 \%$ of the specimens, consistent with the study by Crick et al.; but not with that of Sahni et al., who indicated that only in $70 \%$ of the cases this artery emerges from the RCA and from the circumflex artery in the remaining $30 \%$. The origin of the SAB in humans is variable: From the RCA in $50-79 \%$, from the circumflex artery in 30-45\%, and from both arteries in 3-7\%. (Hadziselimovic et al., 1978; Bokeriya et al., 1984; Krupa, 1993; Cademartiri et al.; Pejkovic et al., 2008; Saremi et al., 2008; Ramonathan et al., 2009; Ballesteros et al., 2010). The high variability observed in the frequency of the origin of the SAB is probably due to the size of the samples evaluated, to the methodology and interpretation of the findings, and to the diverse possibilities of expression of these structures in the diverse population groups. The distance from its emergence to the coronary ostium reported by Sahni et al., is similar to our observations $(17.5 \mathrm{~mm})$ and to what has been reported in humans (16.9$20.3 \mathrm{~mm}$ ) (Bokeriya et al.; Kyriakidis et al., 1988; Ortale et al., 2006; Pejkovic et al.; Zhang et al., 2008; Ballesteros et al., 2011). Concerning the diameter of the SAB, no prior data in pigs are available, whereas in humans diameters ranging from 1,3-1.7 $\mathrm{mm}$ have been reported, namely, greater than those recorded in our study $(1.1 \mathrm{~mm})$ (Nerantzis \& Avgoustakis, 1980; Bokeriya et al.; Ortale et al., 2006; Pejkovic et al.; Saremi et al.; Zhang et al.; Ballesteros et al., 2011). The difference in the diameters of these vessels may be attributed to the different preparation and measurement methodologies and to the weight and height of the evaluated subjects.

The AVNB emerging from the RCA observed in our study in $100 \%$ of the specimens is consistent with the reports by Sahni et al., and Crick et al., In humans this artery has been reported to emerge from the LRVB of the RCA in a range of $85-92 \%$, a number that is similar to our findings; the only difference resides in that in the remaining percentage emerge directly from the RCA in pigs, whereas it emerges from the circumflex artery (8\%) in humans (James \& Burch; Vieweg et al., 1975; Hutchinson et al., 1978; Bokeriya et al.; Futami et al., 2003; Berdajs et al., 2006; Pejkovic et al.; Saremi et al.; Ramonathan et al.; Ballesteros et al., 2011). In humans, the origin of the AVNB has been said to be influenced by the type of coronary dominance. In subjects with right dominance, the AVNB originates from the LRVB, whereas in subjects with left dominance it stems out from the circumflex artery (Bokeriya et al.; Saremi et al.). The distance between the emergence of the AVNB and the bifurcation of the RCA found in the present work $(9.21 \mathrm{~mm})$ is similar to the distance reported by Ballesteros et al. (2011), in humans.

The anastomosis found between the terminal 
branches of the PIB and the anterior interventricular branch, demonstrates the importance of this morphologic expression as protective of the irrigation of the heart, a feature described by Lumb et al., who described it but failed to report the quantitative aspects of this expression.

A posterior right diagonal branch was not observed in any of the hearts evaluated; this structure has not been reported in prior studies in pigs. In humans, it has been referred to as an inconstant structure (frequency of occurrence 12-18\%), which emerges from the RCA at the level of the acute margin of the heart and se runs obliquely over the surface of the posterior wall of the right ventricle until reaching the PIS, thus becoming an alternative for the irrigation of the lower segment of the interventricular septum and of the posterior wall of the right ventricle when both the PIB and the right ventricular branches are short (Margaris et al.; Nerantzis et al.; Kosar et al.; Ballesteros et al., 2011).

\section{CONCLUSIONS}

The RBC originates from the aorta with a lower frequency with respect to reports from human hearts. It was found to emerge from the SAB at the proximal segment of the RCA in all of the cases, whereas in humans this vessel has been described to originate in a high percentage of the cases from the circumflex artery.

The diameter of the RCA and its branches in adult pigs is similar to the diameter reported in humans. The posterior right diagonal branch does not occur in pigs; in humans, although inconstant, its presence should be considered.

The AVNB stems out of the LRVB in the vast majority of the cases, and with a lower frequency directly from the RCA. In humans it also originates from the LRVB in the vast majority of the cases, and with a lower frequency from the circumflex branch, depending on coronary dominance status.

The qualitative and morphometric knowledge of the RCA in pigs supports the utilization of this species for experimental models.

\section{ACKNOWLEDGEMENTS}

To Vijagual Refrigerating Plant in the city of Bucaramanga - Colombia, and to Dr. Luz Stella Cortés, DMV, for donating the pieces for this investigation.

GÓMEZ, F. A. \& BALLESTEROS, L. E. Estudio anatómico de la arteria coronaria derecha en cerdos. Revisión de sus características en comparación con la del humano. Int. J. Morphol., 31(4):1289-1296, 2013.

RESUMEN: Los escasos estudios realizados con relación a la morfología de las arterias coronarias en porcinos enfatizan en descripciones de sus trayectorias y número de ramas. El objetivo del estudio fue determinar la expresión anatómica de la arteria coronaria derecha (ACD) en cerdos de razas comerciales. Fueron estudiados 158 corazones extraídos de cerdos destinados al sacrificio. Las ACD fueron perfundidas con resina poliéster (Palatal 85\% y Estireno15\%) y posteriormente sometidas a infusión de KOH durante 5 minutos para liberar la grasa subepicárdica. Se midieron calibres y evaluaron trayectorias. El calibre de la ACD en su porción proximal fue 3,85 mm (DE 0,75). La arteria derecha del cono se originó de la ACD en 100 especímenes $(92,6 \%)$ y de la aorta (tercera coronaria) en 8 $(7,4 \%)$. La arteria interventricular posterior (AIP) alcanzó el ápex en la mayoría de los casos (49,3\%.) Su calibre proximal fue 2,75 mm (DE 0,61). La rama del nodo sinusal (RNS) y la rama del nodo atrio ventricular (RNAV) se originaron de la ACD en el $100 \%$ de los especímenes. Los calibres de la RNS y RNAV fueron 1,1 mm (DE 0,30) y 1,16 mm (DE 0,30) respectivamente. No se observó rama posterolateral. Existe concordancia con la mayoría de estudios previos con relación a la emergencia desde la ACD de las ramas RNS y RNAV. El conocimiento morfométrico y cualitativo de la ACD y sus ramas en porcinos, es relevante para el diseño de modelos procedimentales y hemodinámicos.

PALABRAS CLAVE: Porcino; Arteria coronaria derecha; Arteria del nodo sinoatrial; Tercera coronaria.

\section{REFERENCES}

Ballesteros, L. E.; Ramírez, L. M. \& Forero, P. L. Características morfológicas y posibles implicaciones clínicas de las arterias nodales. Rev. Colom. Cardiol., 17(6):1-8, 2010.

Ballesteros, L. E.; Ramírez, L. M. \& Quintero, I. D. Right coronary artery anatomy: anatomical and morphometric analysis. Rev. Bras. Cir. Cardiovasc., 26(2):230-7, 2011.
Baptista, C. A.; DiDio, L. J. \& Teofilovski-Parapid, G. Variation in length and termination of the right coronary artery in man. Jpn. Heart J.,30(6):789-98, 1989.

Berdajs, D.; Künzli, A.; Shurr, U.; Zünd, G.; Turina, M. I. \& Genonni, M. Clinical anatomy of the atrioventricular node artery. J. Heart Valve Dis., 15(2):225-9, 2006. 
Bokeriya, L. A.; Mikhailin, S. I. \& Revishvili, A. S. Anatomical variants of sinoatrial and atrioventricular node arteries. Cor Vasa, 26(3):220-8, 1984.

Cademartiri, F.; La Grutta, L.; Malagò, R.; Alberghina, F.; Meijboom, W.B.; Pugliese, F.; Maffei, E.; Palumbo, A. A.; Aldrovandi, A.; Fusaro, M.; Brambilla, V.; Coruzzi, P.; Midiri, M.; Mollet, N. R. \& Krestin, G. P. Prevalence of anatomical variants and coronary anomalies in 543 consecutive patients studied with 64- slice CT coronary angiography. Eur. Radiol., 18(4):781-91, 2008.

Cavalcanti, J. S.; de Lucena Oliveira, M.; Pais e Melo, A. V. Jr.; Balaban, G.; de Andrade Oliveira, C. L. \& de Lucena Oliveira, E. Anatomic variations of the coronary arteries. Arq. Bras. Cardiol., 65(6):489-92, 1995.

Crick, S. J.; Sheppard, M. N.; Ho, S. Y.; Gebstein, L. \& Anderson, R. H. Anatomy of the pig heart: comparisons with normal human cardiac structure. J. Anat., 193(Pt. 1):105-19, 1998 .

Dodge, J. T. Jr.; Brown, B. G.; Bolson, E. L. \& Dodge, H. T. Lumen diameter of normal human coronary arteries. Influence of age, sex, anatomic variation, and left ventricular hypertrophy or dilatation. Circulation, 86(1):332-46, 1992.

Futami, C.; Tanuma, K.; Tanuma, Y. \& Saito, T. The arterial blood supply of the conducting system in normal human hearts. Surg. Radiol. Anat., 25(1):42-9, 2003.

Hadziselimovic, H. Vascularization of the conducting system in the human heart. Acta Anat., 102(2):105-10, 1978.

Hutchinson, M.C. A study of the atrial arteries in man. J. Anat., 125(Pt. 1):39-54, 1978.

James, T. N. Anatomy of the coronary arteries in health and disease. Circulation, 32(6):1020-33, 1965.

James, T. N. \& Burch, G. E. The atrial coronary arteries in man. Circulation, 17(1):90-8, 1958.

Kato, T.; Yasue, T.; Shoji, Y.; Shimabukuro, S.; Ito, Y.; Goto, S.; Motooka, S.; Uno, T. \& Ojima, A. Angiographic difference in coronary artery of man, dog, pig and monkey. Acta Pathol. Jpn., 37(3):361-73, 1987.

Kalpana, R. A study on principal branches of coronary arteries in humans. J. Anat. Soc. India, 52(2):137-40, 2003.

Kosar, P.; Ergun, E.; Öztürk, C. \& Kosar, U. Anatomic variations and anomalies of the coronary arteries: 64-slice CT angiographic appearance. Diagn. Interv. Radiol., 15(4):27583, 2009.

Krupa, U. The sinuatrial nodal artery in the human heart. Folia Morphol. (Warsz), 52(1):29-37, 1993.
Kyriakidis, M.; Vyssoulis, G.; Barbetseas, J. \& Toutouzas, P. A clinical angiographic study of the arterial blood supply to the sinus node. Chest, 94(5):1054-7, 1988.

López, M.; Ruiz, G.; Ramírez, M. \& Arce, A. Cambios fisiológicos en cerdo de cirugía experimental para trasplante cardíaco. Invest. Salud, 6(1):11-3, 2004.

Lumb, G. \& Singletary, H. P. Blood supply to the atrioventricular node and bundle of His: a comparative study in pig, dog, and man. Am. J. Pathol., 41(1):65-75, 1962.

Margaris, N. G.; Kostopoulos, K. G.; Nerantzis, C. E.; Filippatos, G. S.; Kardaras, F. G.; Salahas, A. I.; Antonellis, J. P.; Ifandis, G. P.; Kranidis, A. I. \& Tavernarakis, A. G. Posterior right diagonal artery. An angiographic study. Angiology, 48(8):6737, 1997.

Miyazaki, M. \& Kato, M. Third coronary artery: its development and function. Acta Cardiol., 43(4):449-57, 1988.

Nerantzis, C. \& Avgoustakis, D. An S-shaped atrial artery supplying the sinus node area. An anatomical study. Chest, 78(2):274-8, 1980.

Nerantzis, C. E.; Gribizi, J. E.; Margaris, N. G.; Antonelis, J. P.; Salahas, T. I. \& Koroxenidis, G. T. Posterior right diagonal artery. Anat. Rec., 238(4):528-32, 1994.

Ortale, J. R.; Meciano, J.; Paccola, A. M.; Leal, J. G. P. G. \& Scaranari, C. A. Anatomía dos ramos lateral, diagonal e ânterosuperior no ventrículo esquerdo do coração humano. Rev. Bras. Cir. Cardiovasc., 20(2):149-58, 2005.

Ortale, J. R.; Paganoti, C. F. \& Marchiori, G. F. Anatomical variations in the human sinuatrial nodal artery. Clinics (São Paulo), 61(6):551-8, 2006.

Pejkovic, B.; Krajnc, I.; Anderhuber, F. \& Kosutic, D. Anatomical aspects of the arterial blood supply to the sinoatrial and atrioventricular nodes of the human heart. J. Int. Med. Res., 36(4):691-8, 2008.

Ramanathan, L.; Shetty, P.; Nayak, S. R.; Krishnamurthy, A.; Chettiar, G. K. \& Chockalingam, A. Origin of the sinoatrial and atrioventricular nodal arteries in South Indians: an angiographic study. Arq. Bras. Cardiol., 92(5):314-9, 330-5, 342-8, 2009.

Sahni, D. \& Jit, I. Origin and size of the coronary arteries in the North-West Indians. Indian Heart J., 41(4):221-8, 1989.

Sahni, D.; Kaur, G. D.; Jit, H. \& Jit, I. Anatomy and distribution of coronary arteries in pig in comparison with man. Indian $J$. Med. Res., 127(6):564-70, 2008.

Saremi, F.; Channual, S.; Abolhoda, A.; Gurudevan, S. V.; Narula, J. \& Milliken, J. C. MDCT of the S-shaped sinoatrial node artery. AJR Am. J. Roentgenol., 190(6):1569-75, 2008. 
Sisson, S.; Grossman, J. \& Getty, R. Anatomía de los animales domésticos. $5^{\text {ta }}$ ed. Barcelona, Salvat, 1995.

Stankovic, I. \& Jesic, M. Morphometric characteristics of the conal coronary artery. MJM, 8(1):2-6, 2004.

van Andel, C. J.; Pistecky, P. V. \& Borst, C. Mechanical properties of porcine and human arteries: implications for coronary anastomotic connectors. Ann. Thorac. Surg., 76(1):58-64, 2003.

Vieweg, W. V.; Alpert, J. S. \& Hagan, A. D. Origin of the sinoatrial node and atrioventricular node arteries in right, mixed, and left inferior emphasis systems. Cathet. Cardiovasc. Diagn., l(4):361-73, 1975.

Vieweg, W. V.; Alpert, J. S. \& Hagan, A. D. Caliber and distribution of normal coronary arterial anatomy. Cathet. Cardiovasc. Diagn., 2(3):269-80, 1976.

Weaver, M. E.; Pantely, G. A.; Bristow, J. D. \& Ladley, H. D. A quantitative study of the anatomy distribution of coronary arteries in swine in comparison with other animals and man. Cardiovasc. Res., 20(12):907-17, 1986.

Zhang, L. J.; Wang, Y. Z.; Huang, W.; Chen, P.; Zhou, C. S. \& Lu, G. M. Anatomical investigation of the sinus node artery using dual-source computed tomography. Circ. J., 72(10):1615-20, 2008.

Zindrou, D.; Taylor, K. M. \& Bagger, J. P. Coronary artery size and disease in UK South Asian and Caucasian men. Eur. J. Cardiothorac. Surg., 29(4):492-5, 2006.
Correspondence to: Luis Ballesteros, MD, MSc

Departamento de Ciencias Básicas

Facultad de Salud

Universidad Industrial de Santander

Cra. 32 \# 29-31 Bucaramanga

COLOMBIA

Email: Iballest56@yahoo.es

Received: 19-02-2013

Accepted: 10-08-2013 